\title{
EFFECT OF TUNED MASS DAMPER AND MULTIPLE TUNED MASS DAMPER ON THE VIBRATION OF CHIMNEY SUBJECTED TO SEISMIC LOAD
}

\author{
Kishor Narwade \\ Student, M. Tech Structural Engineering, \\ Applied Mechanics Department, \\ Government College of Engineering, Karad, \\ Maharashtra, India
}

\begin{abstract}
The number of low and light structures daily is steadily increasing in the construction industry with flexible and very low braking values. Reinforced Concrete (RC) chimneys are widely used in industry. Strong winds and earthquakes damaged many industrial chimneys around the world. The performance of $\mathrm{RC}$ chimneys under dynamic loading is well documented by many researchers. Tuned Mass Dumper (TMD) is a passive energy device used to reduce unwanted vibrations in many structural or structural components. There are few studies on the effects of TMD and MTMD to reduce the effects of chimney seismic events. This paper investigates the effect of a mass damper adjusted for the response of chimneys in seismic excavation. Combined differential equations of motion for chimneys and TMD are derived and solved using Newmark's integration method. The optimal location of the TMD and MTMD is identified by the mode type of the uncontrolled chimney. A TMD is placed where the mode shape amplitude of the chimney is the larger in a fundamental mode and is tuned with the corresponding fundamental modal frequency. The reduction was dependent on the TMD properties, location and optimum properties of the damper. A parametric study is conducted to find the most suitable mass ratio and damping ratio for all cases. The research findings indicate that the MTMDs are more effective than the STMD
\end{abstract}

Keywords - Chimney, TMD, MTMDs, Earthquake, Modal frequency/shape, Multi-mode control, Tuned mass damper

\section{INTRODUCTION}

Reinforced Concrete Chimneys (RC) are widely used in various industries. The height of the chimney affects the ability to transfer the flue gas to the outside environment through the stack effect. Chimneys are regarded as

\author{
Prof. J. P. Patankar \\ Professor, \\ Applied Mechanics Department, \\ Government College of Engineering, Karad, \\ Maharashtra, India
}

geometrically simpler structures and are considered when experiencing seismic terrain movement to achieve the same purpose among other options. Chimneys have been damaged or collapsed due to earthquake movements around the world. The collapse of the RC chimney at the Izmit Tupras refinery in 1999 due to the Kocaeli earthquake can be cited as an example of major financial losses and business interruptions. Structural vibration control is achieved by adding structures with passive or active control systems such as viscous dampers, viscoelastic dampers, tuned mass dampers (TMD), friction dampers, shorted piezoelectric ceramic dampers and magnetic dampers. However, the passive approach of energy dissipation and structural vibration control is widely used in structural systems compared to active or hybrid manual control methods for simplicity of design, operation and maintenance. TMD is a device consisting of mass, spring, and dashpot attached to a structure to attenuate the dynamic response of the structure. Since the frequency of the damper is adjusted to a specific structural frequency, when the frequency is excited, the damper disperses the input energy due to the damper inertia acting on the structure, so that the structural motion and the phase difference resonate. The parameters that affect the response of the main system are the damping and tuning frequency ratios of the TMD system. When these parameters reach their optimal values, the maximum reduction in the number of responses is achieved. Many researchers have been attracted to the use of multiple TMDs (MTMDs) compared to a single TMD (STMD) and have improved MTMD performance. However, the issue of placing a huge mass on top of the structure was still a problem. The latest smart solution made for MTMDs to distribute them along with the height of the structures (MTMDs). The MTMDs are used for vibration control of the different type of structures under different loading conditions. 


\section{International Journal of Engineering Applied Sciences and Technology, 2019 Vol. 4, Issue 3, ISSN No. 2455-2143, Pages 266-276 \\ Published Online July 2019 in IJEAST (http://www.ijeast.com)}

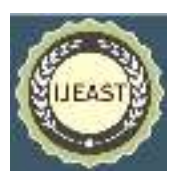

\section{A. Previous Research on TMD Devices}

By the date TMD has been studied by many researchers. The idea of TMD was first used by Frahm in 1909 to reduce not only the hull vibration but also the wavy motion of the ship. Later Hartog developed a vibration analysis model that controlled the force of TMD in 1940. Later we optimized the TMD parameters for sinusoidal stimulation. Fahim et al. (1997) considered other parameters, such as mass ratio, frequency ratio, and damping ratio, to obtain the optimal parameters used to calculate responses of various degrees of freedom and multiple degrees of freedom structures to TMDs in the event of different seismic events. The optimal parameters obtained help to significantly reduce the displacement and acceleration response. Den Hartog clarified the working principle of the device in his monograph [4] and controlled the displacement of the unbalanced single degree of freedom system by providing a simple formula to obtain the optimal tuning and attenuation parameters of the harmonic mass damper power. Kwok and Samali [6], Pinkaew et al. They have proven effective use of TMD to control the response to vibrations of structures subjected to earthquakes and wind. Recently, Brownjohn et al. [1] demonstrated the effectiveness of a tuned mass damper (TMD) to control the response of old chimneys. To improve chimney damping, TMD was installed in an 183-meter chimney. The effective use of tuned mass damper formulas developed for a single degree of freedom system with multiple degrees of freedom has been well documented by several researchers, Example: Reference [02-03]. In these applications, multidimensional free systems are represented by an equivalent single degree of freedom system. This equivalent representation can be successfully used when the response of a multi-degree-offreedom system is governed by a single mode, typically the default mode. Later, Longarini and Zucca [8] reported that TMD improves the seismic response of chimneys in terms of compression and tensile stresses, primary shear and higher displacements. Tuned mass dampers (TMDs) tuned in manual control of vibration response are popular and widely used structural response controls. Chen and $\mathrm{Wu}$ (2004) experimentally studied to reduce the seismic response of a three-story building structure using several tuned mass dampers. They have identified various dynamic characteristics of structures and dampers from free and forced vibration analysis. The structure was analyzed numerically with or without a damper and tested on a vibration table below the white noise. Saidi et al. (2007) developed a tuned mass damper using viscoelastic materials and concluded that TMD is effective when tuning to natural frequencies in narrow bands. It also describes the process for estimating viscous damping of a damper composed of viscoelastic materials. For a given floor mass, damping and stiffness, the damper can be an economical and simple solution for flooring with excessive vibration. It has been verified that multiple control mass dampers (MTMDs) are more effective than dynamic mass dampers (STMDs) in dynamic control of the structural response. Moon [09] showed that a multi-modal mass damper (MTMD) distributed vertically along the entire structure improved the efficiency of the skyscraper response control. Recently, Xiang and Nishitani [16] reported that MTMD is effective for multi-mode control of low-rise buildings that are widely spaced according to seismic excitement. Elias and Matsagar studied the efficiency of a distributed tuned mass damper (d-TMD) to control vibrations through wind in a 76story baseline building [05,06]. However, very limited research has been conducted on the control response to chimney seismicity, in which the location and regulation of the MTMD is performed according to the modal characteristics of the chimney.

\section{B. Objective of the present study}

The purpose of this study is to investigate the effective placement and coordination of TMD depending on the type and shape of the chimney. In this approach, the TMD is placed in the fundamental mode geometry of the chimney and the TMD is tuned to that mode frequency. The MTMD is therefore arranged to suppress the response of the first selected mode of the chimney. To analyze the efficiency of vertically dispersed MTMD with chimney height, compare it to the existing TMD installed at the top of the height chimney. To demonstrate the efficiency of the MTMD deployed according to the mode form, we evaluate the seismic response obtained using:

(i) Single TMD placed at a 5th node;

(ii) Multiple tuned mass damper placed at different nodes

Also, a detailed parametric study is carried out to identify the parameters that affect the response control subject to The 1940 El Centro for a geometrically regular chimney.

\section{THEORY AND MODELING}

The chimney is modeled as a set of beam elements whose vibration degrees of freedom are considered to be dynamic. The theoretical development is based on the assumption that the size of the cross-section in the element, that is, the element of the prismatic beam, remains intact. The additional hypotheses formulated for the analytical formula are as follows.

(i) The chimney is considered to remain within the elastic limit under the excitation of the earthquake in uninterrupted conditions

(ii)The system is subject to a single horizontal (unidirectional) component of the movement of earthquake earth; and 


\section{International Journal of Engineering Applied Sciences and Technology, 2019 Vol. 4, Issue 3, ISSN No. 2455-2143, Pages 266-276 \\ Published Online July 2019 in IJEAST (http://www.ijeast.com)}

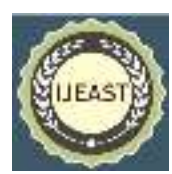

(iii) The effects of soil-structure interaction (SSI) are not taken into account.

\section{A. Mathematical modeling of the chimney-}

The $100 \mathrm{~m}$ high reinforced concrete chimney is considered in this study applied to earthquake motion (El Centro, $1940 \mathrm{~N}-\mathrm{S}$ component). The chimney is divided into five beam elements and the length (li) of each beam element is $20 \mathrm{~m}$ each. The chimney has five degrees of freedom and only the first three modal responses are controlled because $90 \%$ of the seismic mass participates in the first three modes. The outer diameter (D) and the thickness (t) according to the height of the chimney are shown in Table 1 . The modulus of elasticity (Ec) of the concrete is assumed to be $2.5 \times 10^{10} \mathrm{~N} / \mathrm{m}^{2}$, density of the concrete is considered $2400 \mathrm{~kg} / \mathrm{m}^{3}$. The damping matrix is not explicitly known; hence, it is defined with the help of the Rayleigh's approach using damping ratio $(\xi=5 \%)$ in all modes of vibration. Fig. 1,2 shows the model of the chimney, mode shapes of the chimney considered in the study. The governing equations of motion for the chimney installed with the STMD at the top and installed with the MTMDs are obtained by considering the equilibrium of forces at the location of each degree of freedom as follows.

$$
\left[\mathbf{M}_{\mathbf{s}}\right]\left\{\ddot{\mathbf{x}}_{\mathbf{s}}\right\}+\left[\mathbf{C}_{\mathbf{s}}\right]\left\{\ddot{\mathbf{x}}_{\mathbf{s}}\right\}+\left[\mathbf{K}_{\mathbf{s}}\right]\left\{\mathbf{x}_{\mathbf{s}}\right\}=-\left[\mathbf{M}_{\mathbf{s}}\right]\{\mathbf{r}\} \ddot{\mathbf{x}}_{\mathbf{g}}
$$

Where $\left[\mathrm{M}_{\mathrm{s}}\right],\left[\mathrm{C}_{\mathrm{s}}\right]$, and $\left[\mathrm{K}_{\mathrm{s}}\right]$ are the mass, damping, and stiffness matrices of the chimney, respectively of order $(\mathrm{N}+$ n) $x(N+n)$. Here, $N$ indicates degrees of freedom (DOF) for the chimney and $\mathrm{n}$ indicates DOF for the STMD, STMD2. Further, $\quad\left\{\mathrm{x}_{\mathrm{s}}\right\}=\left\{\mathrm{X} 1, \mathrm{X}_{2}, \mathrm{X}_{3}, \mathrm{X}_{\mathrm{n}-1}, \mathrm{X}_{\mathrm{N}}, \mathrm{x}_{1}, \mathrm{x}_{\mathrm{n}},\right\} \mathrm{T}$ are the unknown relative nodal displacement, velocity, and acceleration vectors, respectively. The earthquake ground acceleration is represented by $\ddot{x}_{g}$ and $\{r\}$ is the vector of influence coefficients. The modal frequency and mode geometry of the chimney without TMD is determined by solving the eigenvalue problem. The TMD is placed in a position where the amplitude of the first mode shape of the chimney is larger and is adjusted to its modal frequency. If one TMD is not placed in one position, $\left(\mathrm{k}_{\mathrm{i}}\right)$ and damping $\left(\mathrm{c}_{\mathrm{i}}\right)$ parameters of the TMDs $(i=1 \ldots . n)$ are calculated based on the modal frequencies. For the TMDs, the mass matrix is of $\operatorname{order}(\mathrm{N}+\mathrm{n}) \times(\mathrm{N}+\mathrm{n})$ as follows.

$$
\left[\mathbf{M}_{\mathbf{s}}\right]=\left[\begin{array}{cc}
{\left[\mathbf{M}_{\mathbf{N}}\right]_{\mathbf{N} \times \mathbf{N}}} & {[\mathbf{0}]_{\mathrm{N} \times \mathbf{n}}} \\
{[\mathbf{0}]_{\mathbf{n} \times \mathbf{N}}} & {\left[\mathbf{m}_{\mathbf{n}}\right]_{\mathbf{n} \times \mathbf{n}}}
\end{array}\right]
$$

Where $\left[\mathrm{M}_{\mathrm{N}}\right]_{\mathrm{N} \times \mathrm{N}}$ shows the mass matrix for the chimney and $\left[\mathrm{m}_{\mathrm{n}}\right]_{\mathrm{n} \times \mathrm{n}}$ indicates the mass matrix of the TMDs. In Eq. (2), for obtaining mass matrix corresponding to the STMD $n=1$ is considered. The condensed stiffness matrix $\left[\mathrm{K}_{\mathrm{N}}\right]_{\mathrm{N} \times \mathrm{N}}$ is corresponding to the sway degrees of freedom taken as the dynamic DOF. The damping matrix $\left[\mathrm{C}_{\mathrm{N}}\right]_{\mathrm{N} \times \mathrm{N}}$ is not explicitly known but is obtained with the help of the Rayleigh's approach using the same damping ratio in all nodes. The stiffness matrix, $\left[\mathrm{K}_{\mathrm{n}}\right]_{\mathrm{n} \times \mathrm{n}}$ and damping matrix, $\left[\mathrm{C}_{\mathrm{n}}\right]_{\mathrm{n} \times \mathrm{n}}$ are expressed corresponding to the degrees of freedom associated with the TMDs. For the chimney installed with the STMD or MTMDs, stiffness and damping of the TMDs are inputs in the generic stiffness matrix $\left[\mathrm{K}_{\mathrm{s}}\right]$ and damping matrix $\left[\mathrm{C}_{\mathrm{s}}\right]$ as follows.

$$
\left[\mathbf{K}_{\mathrm{s}}\right]=\left[\left[\begin{array}{cc}
{\left[\mathbf{K}_{\mathrm{N}}\right]_{\mathrm{N} \times \mathrm{N}}} & {[\mathbf{0}]_{\mathrm{N} \times \mathbf{n}}} \\
{[\mathbf{0}]_{\mathrm{n} \times \mathrm{N}}} & {[\mathbf{0}]_{\mathrm{n} \times \mathbf{n}}}
\end{array}\right]+\left[\begin{array}{cc}
{\left[\mathbf{K}_{\mathrm{n}}\right]_{\mathrm{N} \times \mathrm{N}}} & -\left[\mathbf{K}_{\mathbf{n}}\right]_{\mathrm{N} \times \mathbf{n}} \\
-\left[\mathbf{K}_{\mathbf{n}}\right]_{\mathrm{n} \times \mathbf{N}} & {\left[\mathbf{K}_{\mathbf{n}}\right]_{\mathrm{n} \times \mathbf{n}}}
\end{array}\right]\right]_{(\mathrm{N}+\mathrm{n}) \times(\mathrm{N}+\mathrm{n})}
$$

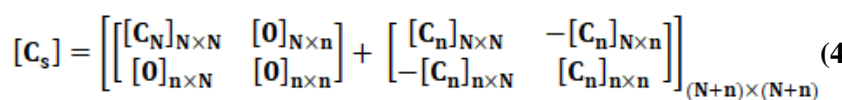

The coupled differential equations of motion (Eq. (1)) for the chimney installed with $\mathrm{TMD}(\mathrm{s})$ are thus derived and solved using Newmark's integration method.

\section{B. Designing and placement of STMD/MTMDs -}

Based on modal mass participation of $90 \%$ or more as a deciding criterion, first three modal responses are controlled using the TMDs.

The effectiveness of the TMD installed on a chimney depends on mass ratio,

$$
\mu=\frac{\mathbf{m}_{t}}{\mathbf{M}_{\mathrm{t}}}
$$

where $m_{t}$ is the total mass of the TMDs, Mt is mass of the chimney. Frequency ratio $f$ is defined as the ratio of the fundamental frequency of the damper to the natural frequency of a SDOF system

$$
f=\frac{\omega_{\mathrm{d}}}{\omega}
$$

where $\omega_{\mathrm{d}}$ frequency of damper, $\omega$ is the frequency of chimney. The TMD damping ratio $\xi \mathrm{d}$ defined as

$$
\xi_{d}=\frac{c_{d}}{2 m_{d} \omega_{d}}
$$

The stiffness $\left(k_{i}\right)$ is used for adjusting the frequency of each TMD unit such that,

$$
k_{i}=m_{i} \times w_{i}^{2}
$$


International Journal of Engineering Applied Sciences and Technology, 2019

Vol. 4, Issue 3, ISSN No. 2455-2143, Pages 266-276

Published Online July 2019 in IJEAST (http://www.ijeast.com)

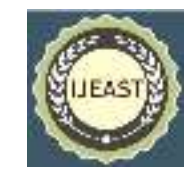

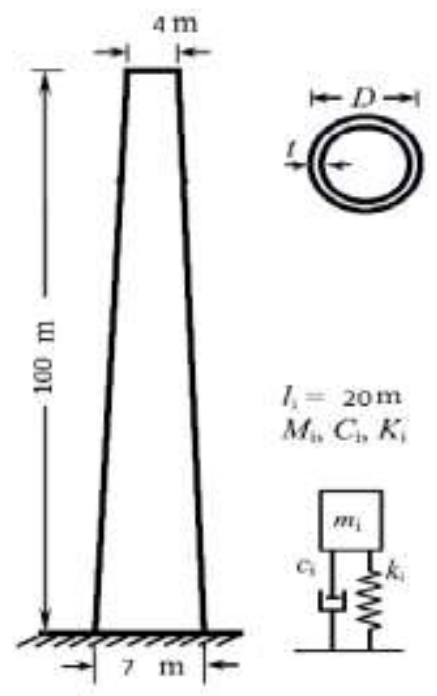

Fig -1: Details of the regular

Damper placement is the most important consideration in controlling the dynamic response of chimneys due to seismic vibrations. Generally, the STMD is located at the top of the chimney which experiences a large displacement in the first mode of vibration. For MTMD, a modal analysis is performed to find the mode shape and modal frequency of the chimney. The TMD of the multi-mode control strategy is placed where the amplitude of the first mode shape is larger, and each TMD is tuned to the corresponding mode frequency. Figure 3 shows the placement of the MTMD along with the height of the chimney in the uncontrolled normalized mode, as shown in Figure 2 and demonstrates the seismic analysis and design of the structure to be built in a specific location. However, it is not possible to have such records at each and every location. Further, the seismic analysis of structures cannot be carried out simply based on the peak value of the ground acceleration as the response of the structure depend upon the frequency content of ground motion and its dynamic properties. To overcome the above difficulties, the earthquake response spectrum is the most popular tool in the seismic analysis of structures. There are computational advantages in using the response spectrum method of seismic analysis for prediction of displacements and member forces in each mode of vibration using smooth design spectra that are the average of several earthquake motions. To calculate the value of response of MDOF system with single-support earthquake excitation solution is obtained by State Space Method. Earthquake ground motion considered is 'El Centro, 1940 (N-S component)'.

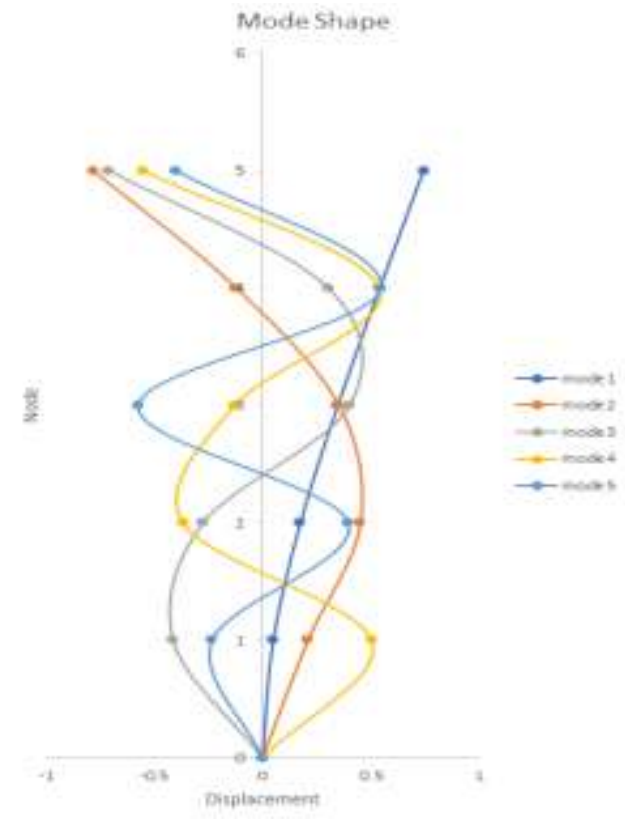

Fig -2: Mode shape of the regular chimney.

Usually, the response of a SDOF system is determined by time domain or frequency domain analysis, and for a given time of the system, the maximum response is picked. This process is continued for all range of possible periods of SDOF system. By using the state-space method we can calculate the maximum displacement at each node, maximum absolute displacement at each node, maximum absolute acceleration, RMS displacement, and RMS absolute acceleration. The equation of motion can then be converted to a state-space equation as follows:

$$
\mathbf{Z}=\mathbf{A Z}+\mathbf{H} \ddot{\mathbf{X}}_{\mathbf{g}}(\mathbf{t})
$$

$Z(t)=\left[\begin{array}{c}X_{t} \\ \ddot{X}_{t}\end{array}\right] A=\left[\begin{array}{cc}0 & 1 \\ -M^{-1} \mathbf{K} & -M^{-1} \mathbf{C}\end{array}\right] H=\left[\begin{array}{c}0 \\ M^{-1} \mathbf{m}\end{array}\right]$

By transforming the equation of motion to the state space equation, the second-order-order differential equation is transformed into the first-order one. In this case, the transfer function is given by

$$
\mathbf{G}(\mathbf{i} \omega)=\mathbf{C}_{\mathbf{y}}(\mathbf{i} \omega \mathbf{I}-\mathbf{A})^{-1} \mathrm{H}
$$

Where $\mathbf{C}_{\mathbf{y}}$ is the $2 \times(n+1)$-dimensional output matrix; $I$ is the identity matrix and $\omega$ is the circular frequency argument. 
International Journal of Engineering Applied Sciences and Technology, 2019

Vol. 4, Issue 3, ISSN No. 2455-2143, Pages 266-276

Published Online July 2019 in IJEAST (http://www.ijeast.com)

Table -1: Geometric data for chimney

\begin{tabular}{|c|c|c|c|}
\hline $\begin{array}{c}\text { Distance } \\
\text { from } \\
\text { base }\end{array}$ & $\begin{array}{c}\text { Outer } \\
\text { Diameter } \\
(\mathrm{m})\end{array}$ & $\begin{array}{c}\text { Thickness } \\
\text { of the } \\
\text { chimney } \\
(\mathrm{m})\end{array}$ & $\begin{array}{c}\text { Inner } \\
\text { Diameter } \\
(\mathrm{m})\end{array}$ \\
\hline 0 & 7 & $\mathbf{0 . 4}$ & 6.6 \\
\hline 20 & 6.4 & 0.36 & 6.04 \\
\hline 40 & 5.8 & 0.32 & 5.48 \\
\hline 60 & 5.2 & 0.28 & 4.92 \\
\hline 80 & 4.6 & 0.24 & 4.36 \\
\hline 100 & 4 & 0.2 & 3.8 \\
\hline & & \multicolumn{3}{|c}{} \\
\hline
\end{tabular}

In this study for calculating the maximum displacement at each node, maximum absolute displacement at each node, maximum absolute acceleration, RMS displacement, and RMS absolute acceleration is calculated by using State-Space Method for this chimney shown in fig (1)

Table -1: Results of regular chimney

\begin{tabular}{|c|c|c|}
\hline $\begin{array}{c}\text { Result of State Space } \\
\text { Method }\end{array}$ & Result & Node \\
& & \\
\hline Max_D1 & $\mathbf{0 . 1 0 3 7 0 8 3 0 4}$ & $\mathbf{1}$ \\
\hline Max_D2 & $\mathbf{0 . 2 3 1 1 9 5 4 6 3}$ & $\mathbf{2}$ \\
\hline Max_D3 & $\mathbf{0 . 3 5 6 0 9 7 7 9 7}$ & $\mathbf{3}$ \\
\hline Max_D4 & $\mathbf{0 . 4 1 3 1 2 0 2 5}$ & $\mathbf{4}$ \\
\hline Max_D5 & $\mathbf{0 . 6 2 2 0 3 4 9 3 6}$ & $\mathbf{5}$ \\
\hline Max_a_abs_1 & $\mathbf{1 . 2 8 5 6 1 0 4 7 6}$ & $\mathbf{1}$ \\
\hline Max_a_abs_2 & $\mathbf{1 . 0 2 2 2 5 7 2 8 9}$ & $\mathbf{2}$ \\
\hline Max_a_ab_3 & $\mathbf{0 . 8 8 1 3 7 1 3 0 4}$ & $\mathbf{3}$ \\
\hline Max_a_abs_4 & $\mathbf{1 . 3 4 9 6 1 4 1 0 8}$ & $\mathbf{4}$ \\
\hline Max_a_abs_5 & $\mathbf{1 . 8 5 5 8 2 3 9 3 6}$ & $\mathbf{5}$ \\
\hline RMS_d1 & $\mathbf{0 . 0 4 4 4 0 4 0 8 6}$ & $\mathbf{1}$ \\
\hline RMS_d2 & $\mathbf{0 . 0 6 3 7 1 6 3 2 4}$ & $\mathbf{2}$ \\
\hline RMS_d3 & $\mathbf{0 . 0 6 1 0 9 2 5 1 8}$ & $\mathbf{3}$ \\
\hline RMS_d4 & $\mathbf{0 . 0 3 8 0 4 1 5 2 4}$ & $\mathbf{4}$ \\
\hline RMS_d5 & $\mathbf{0 . 0 4 0 8 4 8 6 5 5}$ & $\mathbf{5}$ \\
\hline RMS_a_abs_1 & $\mathbf{0 . 2 1 8 6 7 4 9 6}$ & $\mathbf{1}$ \\
\hline RMS_a_abs_2 & $\mathbf{0 . 1 8 8 3 8 6 6 6 9}$ & $\mathbf{2}$ \\
\hline RMS_a_abs_3 & $\mathbf{0 . 1 9 5 4 7 2 9 8}$ & $\mathbf{3}$ \\
\hline RMS_a_abs_4 & $\mathbf{0 . 2 2 8 5 7 8 9 4 4}$ & $\mathbf{4}$ \\
\hline RMS_a_abs_5 & $\mathbf{0 . 3 2 8 3 9 4 4 9 4}$ & $\mathbf{5}$ \\
\hline
\end{tabular}

But the main effect to the chimney is due to maximum deflection so in this study maximum displacement results are considered

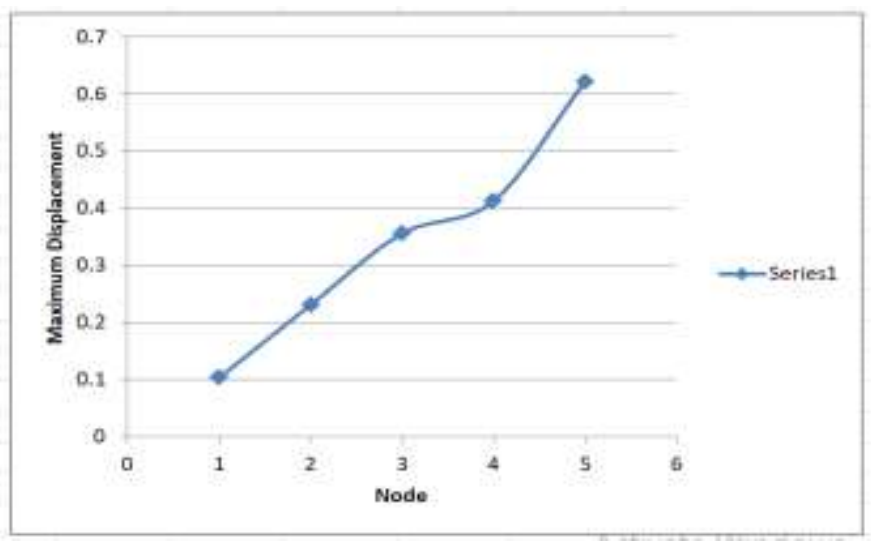

Chart.1: Maximum Displacement of Chimney

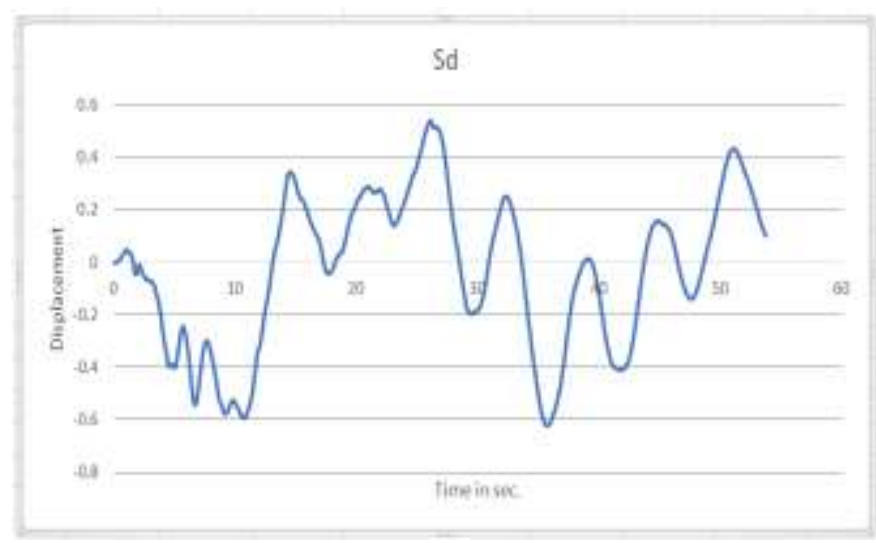

Chart.2: Displacement of the 5th node of the chimney

After using the Newmark $\beta$ method for 5\% damping, using $0.08 \mathrm{sec}$. the critical time is considered and used it for $200 \mathrm{sec}$.

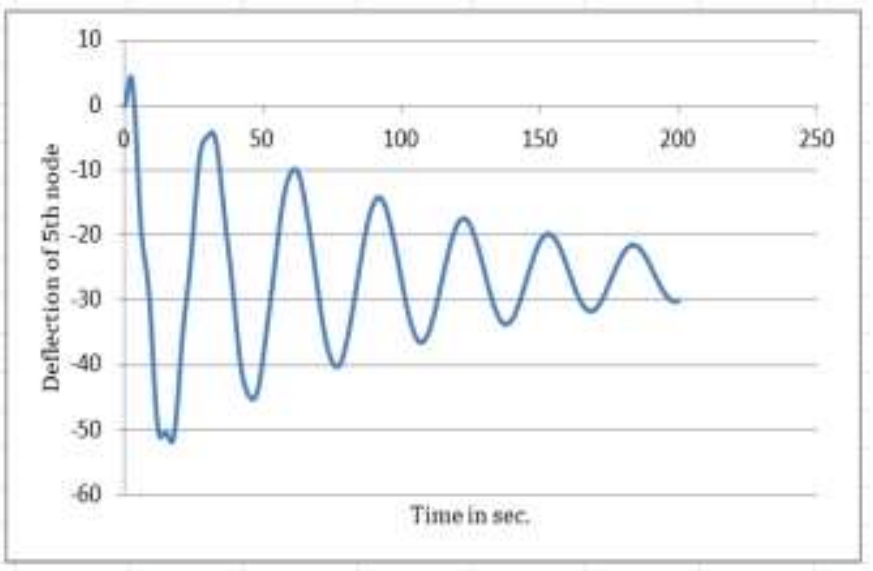

Chart.3: Displacement of the $5^{\text {th }}$ node of the chimney using Newmark $\beta$ method 
International Journal of Engineering Applied Sciences and Technology, 2019

Vol. 4, Issue 3, ISSN No. 2455-2143, Pages 266-276

Published Online July 2019 in IJEAST (http://www.ijeast.com)

So to reduce the deflection of the $5^{\text {th }}$ node by considering the first mode of vibration and different percentage of TMD is used which is nothing but a single tuned mass damper.

Table -2: Position of Single Tuned Mass Damper

\begin{tabular}{|c|c|c|c|c|c|c|}
\hline \multirow{2}{*}{$\begin{array}{c}\text { node } \\
\text { no. }\end{array}$} & \multicolumn{6}{|c|}{ Percentage of Single tuned mass damper } \\
\cline { 2 - 7 } & $\mathbf{0 . 5}$ & $\mathbf{1}$ & $\mathbf{1 . 5}$ & $\mathbf{2}$ & $\mathbf{2 . 5}$ & $\mathbf{3}$ \\
\hline 5 & STMD & STMD & STMD & STMD & STMD & STMD \\
\hline 4 & - & - & - & - & - & - \\
\hline 3 & - & - & - & - & - & - \\
\hline 2 & - & - & - & - & - & - \\
\hline 1 & - & - & - & - & - & - \\
\hline
\end{tabular}

After using the different percentage of tuned mass damper Maximum deflection of the 5th node is observed using the Newmark method for the first modal frequency only.

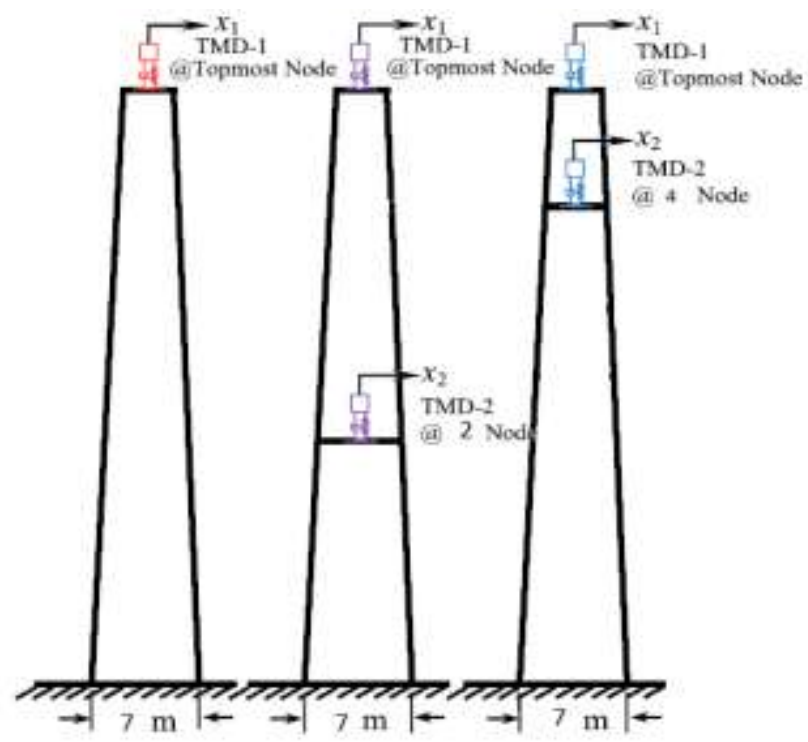

Fig -3: Distribution of single and multiple TMD

III. RESULTS AND DISCUSSIONS

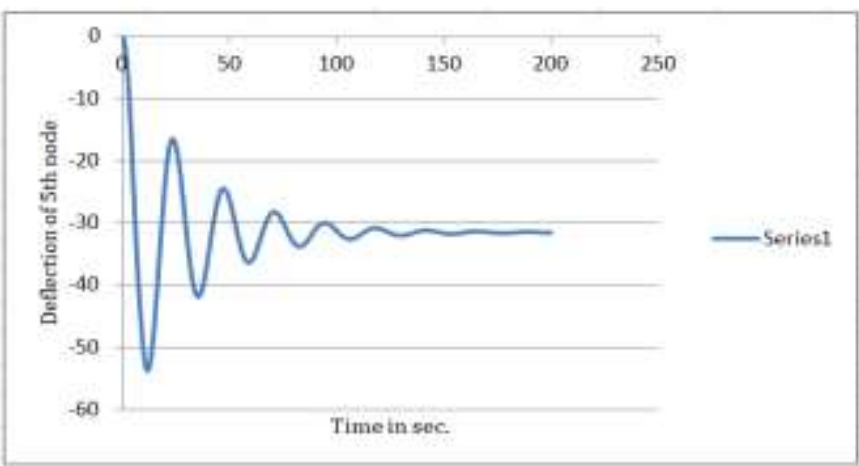

Chart -4: Displacement of 5th node of chimney using 0.5\% TMD at 5th node

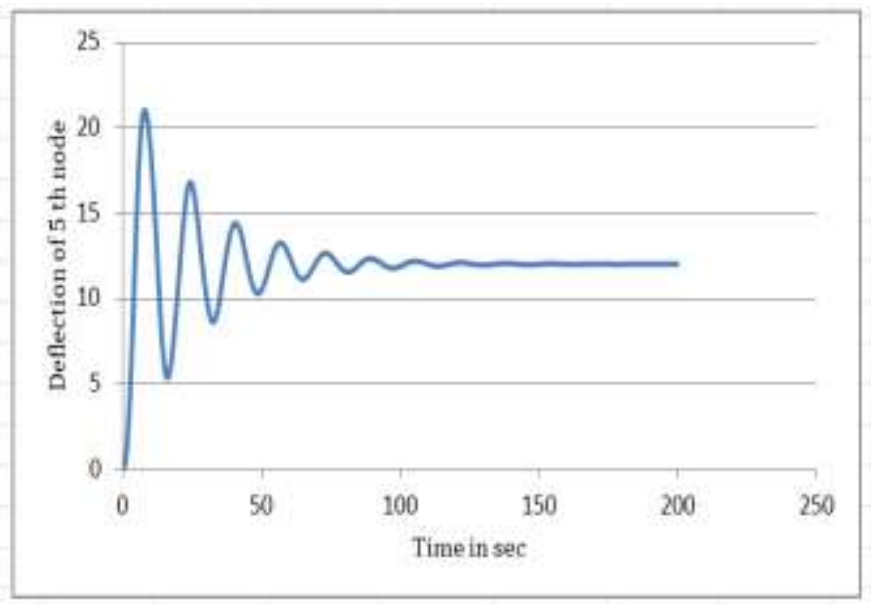

Chart -5: Displacement of the 5th node of the chimney using $1 \%$ TMD at 5 th node

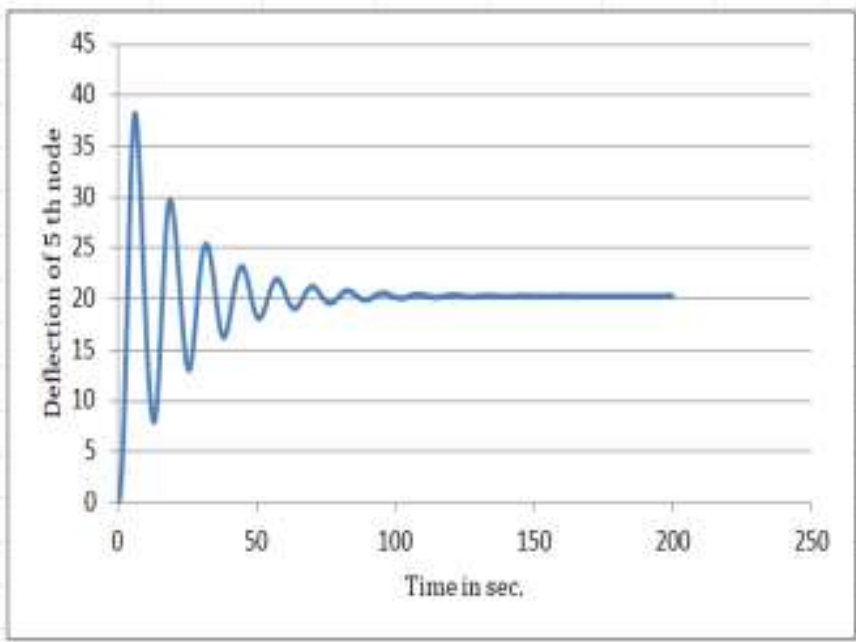

Chart -6 : Displacement of the $5^{\text {th }}$ node of the chimney using $1.5 \%$ TMD at $5^{\text {th }}$ node

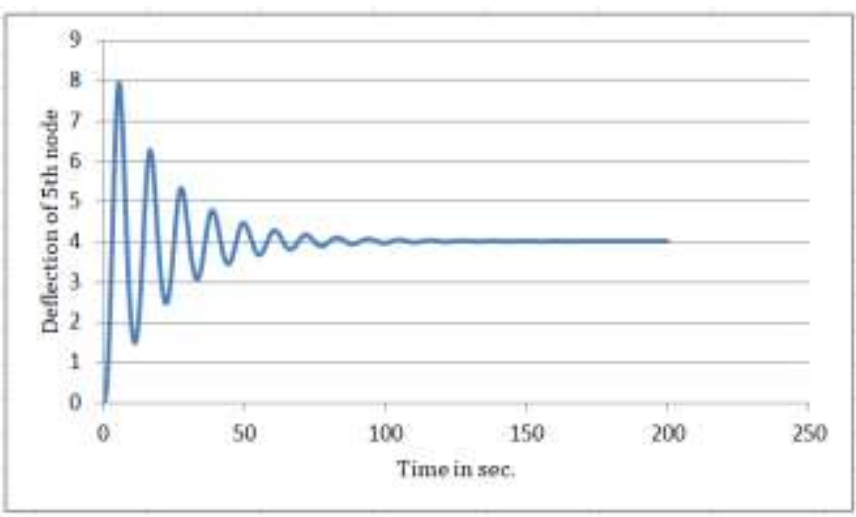

Chart -7: Displacement of the $5^{\text {th }}$ node of the chimney using $2 \%$ TMD at $5^{\text {th }}$ node 
International Journal of Engineering Applied Sciences and Technology, 2019

Vol. 4, Issue 3, ISSN No. 2455-2143, Pages 266-276

Published Online July 2019 in IJEAST (http://www.ijeast.com)

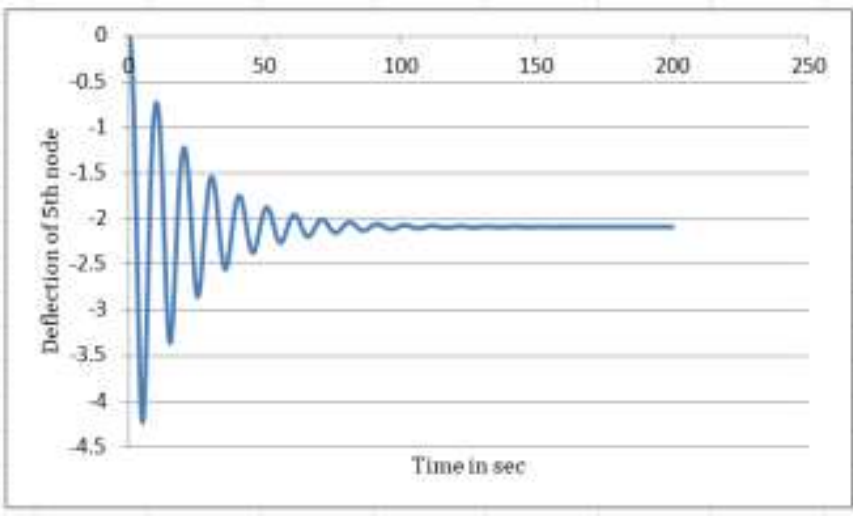

Chart -8: Displacement of the $5^{\text {th }}$ node of the chimney using $2.5 \%$ TMD at $5^{\text {th }}$ node

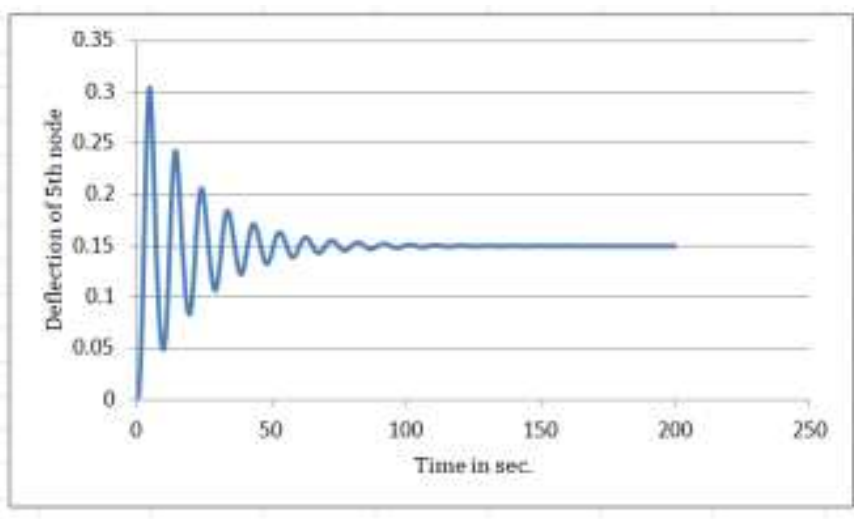

Chart -9: Displacement of the $5^{\text {th }}$ node of the chimney using $3 \%$ TMD at the $5^{\text {th }}$ node

Comparison of percentage damping is carried out using the result obtained by using state-space method

Table -3: Results for different percentage damping

\begin{tabular}{|c|c|c|c|c|c|c|}
\hline \multirow{2}{*}{ result } & \multicolumn{6}{|c|}{ percentage damping } \\
\hline & 0.5 & 1 & 1.5 & 2 & 2.5 & 3 \\
\hline Max_D1 & 0.103327409 & 0.106248 & 0.107857 & 0.110925 & 0.116041 & 0.12296 \\
\hline Max_D2 & 0.149311324 & 0.175577 & 0.239272 & 0.269374 & 0.286641 & 0.272218 \\
\hline Max_D3 & 0.275450692 & 0.270535 & 0.345202 & 0.418307 & 0.438244 & 0.412318 \\
\hline Max_D4 & 0.320799937 & 0.364831 & 0.390189 & 0.438118 & 0.431062 & 0.379377 \\
\hline Max_D5 & 0.510029907 & 0.491016 & 0.430975 & 0.363585 & 0.238587 & 0.174682 \\
\hline Max_a_abs_1 & 1.456719085 & 1.43817 & 1.416996 & 1.39654 & 1.382029 & 1.377532 \\
\hline Max_a_abs_2 & $\mathbf{1 . 4 8 6 9 2 7 5 5 3}$ & 1.461987 & 1.430983 & 1.401776 & 1.379448 & 1.363932 \\
\hline Max_a_abs_3 & 0.948235655 & 0.937653 & 0.918609 & 0.899319 & 0.90301 & 0.911464 \\
\hline Max_a_abs_4 & 1.672161464 & 1.680788 & 1.67608 & 1.666052 & 1.647612 & 1.62266 \\
\hline Max_a_abs_5 & 1.611397154 & 1.377219 & 1.196732 & 1.069719 & 0.998134 & 0.963365 \\
\hline RMS_d1 & 0.032632434 & 0.032761 & 0.037199 & 0.040398 & 0.045215 & 0.048962 \\
\hline RMS_d2 & 0.044226852 & 0.045761 & 0.055846 & 0.061252 & 0.068976 & 0.074639 \\
\hline RMS_d3 & 0.040848486 & 0.046947 & 0.063801 & 0.069482 & 0.076919 & 0.08193 \\
\hline RMS_d4 & 0.025169786 & 0.043578 & 0.067421 & 0.070975 & 0.074285 & 0.075662 \\
\hline RMS_d5 & 0.025110843 & 0.039109 & 0.06924 & 0.068766 & 0.064496 & 0.058662 \\
\hline RMS_a_abs_1 & 0.242797057 & 0.239143 & 0.235973 & 0.233667 & 0.232534 & 0.232445 \\
\hline RMS_a_abs_2 & 0.267019408 & 0.251512 & 0.23895 & 0.230404 & 0.225731 & 0.222914 \\
\hline RMS_a_abs_3 & 0.233645061 & 0.218907 & 0.208987 & 0.203495 & 0.201608 & 0.20068 \\
\hline RMS_a_abs_4 & 0.315920138 & 0.304482 & 0.297887 & 0.292483 & 0.288267 & 0.28473 \\
\hline RMS_a_abs_5 & 0.277715996 & 0.238645 & 0.209675 & 0.18626 & 0.172986 & 0.166705 \\
\hline
\end{tabular}


International Journal of Engineering Applied Sciences and Technology, 2019

Vol. 4, Issue 3, ISSN No. 2455-2143, Pages 266-276

Published Online July 2019 in IJEAST (http://www.ijeast.com)

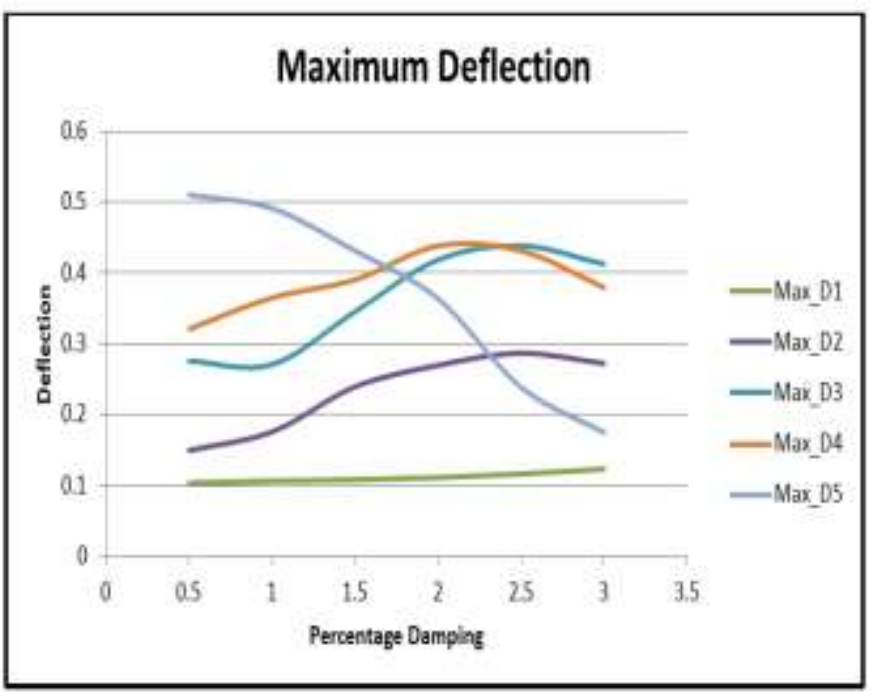

Chart -10: Maximum Displacement of the Chimney using different TMD at the 5th node

By considering the result obtained in the above table, $1.5 \%$ TMD is more effective than other dampers. So for further study of multiple tuned mass dampers, the $1.5 \%$ TMD is investigated. The position of multiple tuned mass dampers is given in the table below. The chimney is investigated by using two TMD at a time and its maximum displacement at each node, maximum absolute displacement at each node, maximum absolute acceleration, RMS displacement and RMS absolute acceleration for each node but all the calculations are observed for fundamental frequency only.

Table -4: Position of Multiple Tuned Mass Damper

\begin{tabular}{|c|c|c|c|c|}
\hline \multirow{2}{*}{ Node no. } & \multicolumn{5}{|c|}{ Percentage of Single tuned mass damper } \\
\cline { 2 - 5 } & 1.5 & 1.5 & 1.5 & 1.5 \\
\hline 5 & STMD & STMD & STMD & STMD \\
\hline 4 & STMD & - & - & - \\
\hline 3 & - & STMD & - & - \\
\hline 2 & - & - & STMD & - \\
\hline 1 & - & - & - & STMD \\
\hline
\end{tabular}

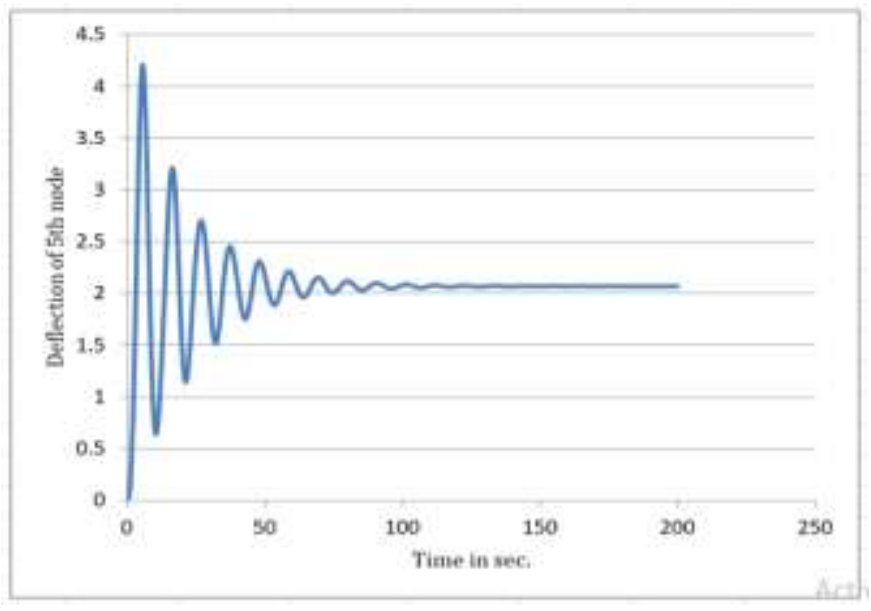

Chart -11: Displacement of the 5th node of the chimney using $1.5 \%$ TMD at 5 th and 4 th node

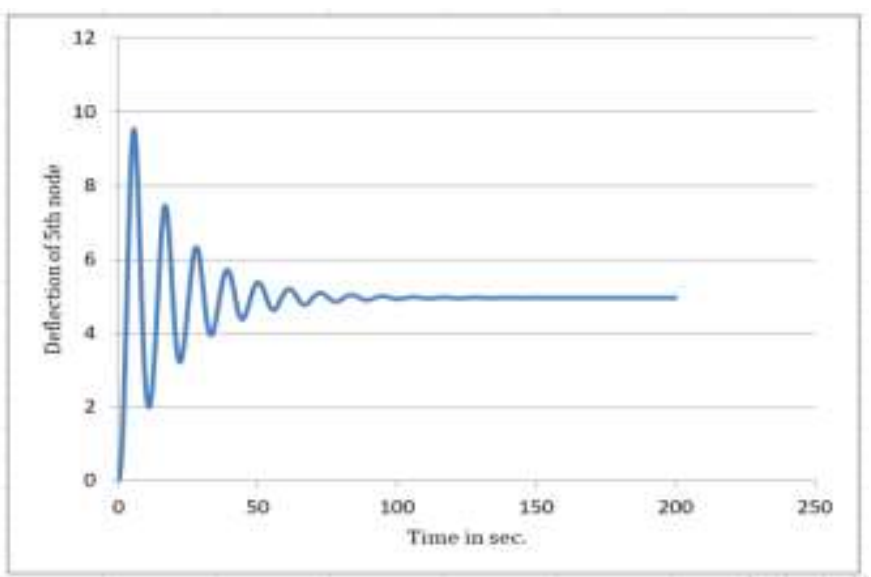

Chart -12: Displacement of the 5th node of the chimney using $1.5 \%$ TMD at 5 th and 3rd node

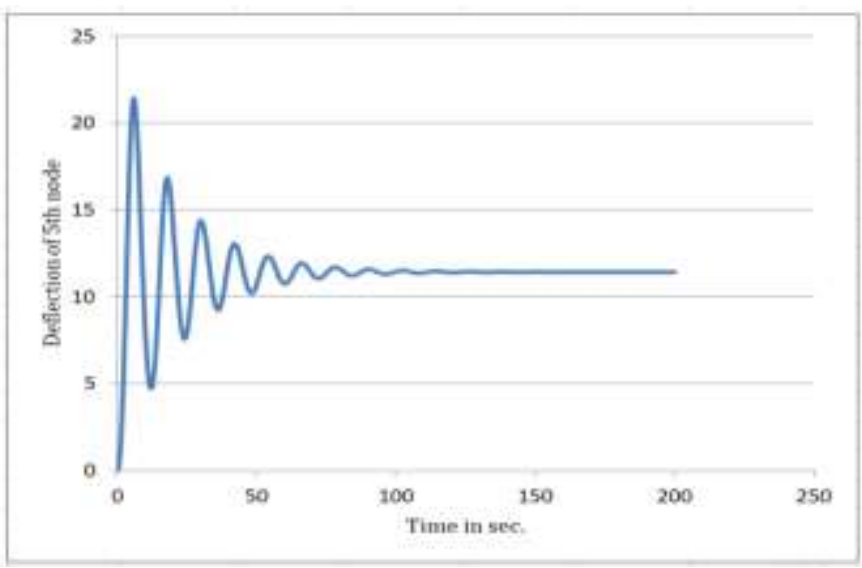

Chart -13: Displacement of the 5th node of the chimney using $1.5 \%$ TMD at 5 th and 2 nd node 
International Journal of Engineering Applied Sciences and Technology, 2019

Vol. 4, Issue 3, ISSN No. 2455-2143, Pages 266-276

Published Online July 2019 in IJEAST (http://www.ijeast.com)

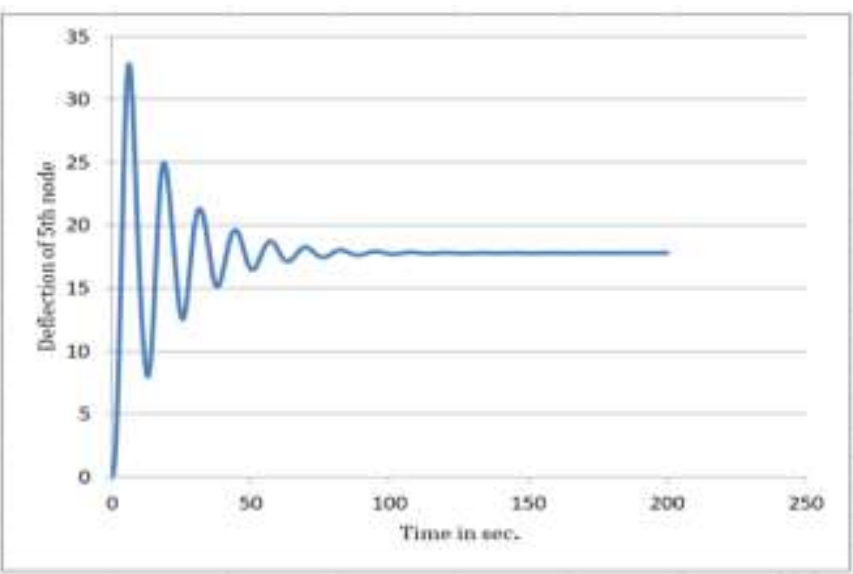

Chart -14: Displacement of the 5th node of the chimney using $1.5 \%$ TMD at 5 th and 1 st node

The maximum deflection of the $5^{\text {th }}$ node is investigated by using $1.5 \%$ Multiple TMD on different nodes and results are observed.

Table -5: Results for MTMD at different nodes

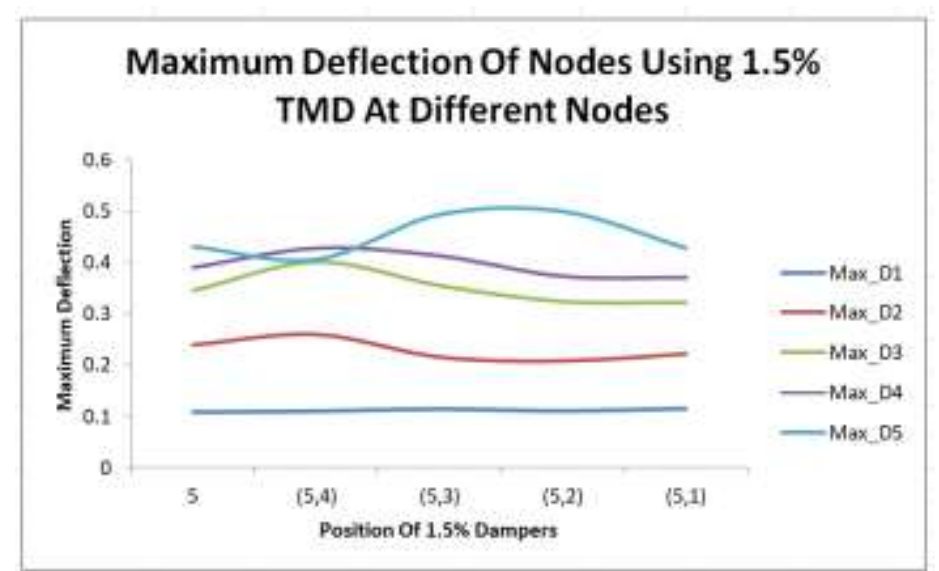

Chart -15: Maximum Displacement of Chimney using MTMD at different node

\begin{tabular}{|c|c|c|c|c|c|}
\hline \multirow{2}{*}{ Result } & \multicolumn{5}{|c|}{$1.5 \%$ TMD damper attached at nodes } \\
\hline & 5 & 5,4 & 5,3 & 5,2 & 5,1 \\
\hline Max_D1 & 0.107857 & 0.109876 & 0.113916 & 0.110313 & 0.114989 \\
\hline Max_D2 & 0.239272 & 0.259646 & 0.215398 & 0.207875 & 0.221734 \\
\hline Max_D3 & 0.345202 & 0.401304 & 0.355131 & 0.323892 & 0.322309 \\
\hline Max_D4 & 0.390189 & 0.427972 & 0.413149 & 0.37316 & 0.370598 \\
\hline Max_D5 & 0.430975 & 0.405977 & 0.493681 & 0.499817 & 0.428212 \\
\hline Max_a_abs_1 & 1.416996 & 1.320192 & 1.384202 & 1.333774 & 1.244116 \\
\hline Max_a_abs_2 & 1.430983 & 1.35986 & 1.402432 & 1.142174 & 1.366138 \\
\hline Max_a_abs_3 & 0.918609 & 0.953451 & 0.854283 & 0.933756 & 0.919445 \\
\hline Max_a_abs_4 & 1.67608 & 1.247859 & 1.502841 & 1.498569 & 1.573708 \\
\hline Max_a_abs_5 & 1.196732 & 1.095647 & 1.049901 & 1.112211 & 1.174762 \\
\hline RMS_d1 & 0.037199 & 0.036288 & 0.033491 & 0.033893 & 0.036454 \\
\hline RMS_d2 & 0.055846 & 0.054403 & 0.048493 & 0.049539 & 0.052263 \\
\hline RMS_d3 & 0.063801 & 0.061103 & 0.053321 & 0.05601 & 0.056868 \\
\hline RMS_d4 & 0.067421 & 0.063184 & 0.055685 & 0.059875 & 0.05946 \\
\hline RMS_d5 & 0.06924 & 0.065111 & 0.05732 & 0.062733 & 0.062613 \\
\hline RMS_a_abs_1 & 0.235973 & 0.219512 & 0.225497 & 0.233317 & 0.216487 \\
\hline RMS_a_abs_2 & 0.23895 & 0.233622 & 0.230842 & 0.189332 & 0.227126 \\
\hline RMS_a_abs_3 & 0.208987 & 0.205871 & 0.174802 & 0.188365 & 0.198529 \\
\hline RMS_a_abs_4 & 0.297887 & 0.223365 & 0.285645 & 0.278093 & 0.27915 \\
\hline RMS_a_abs_5 & 0.209675 & 0.204545 & 0.205127 & 0.210776 & 0.217275 \\
\hline
\end{tabular}




\section{International Journal of Engineering Applied Sciences and Technology, 2019 Vol. 4, Issue 3, ISSN No. 2455-2143, Pages 266-276 \\ Published Online July 2019 in IJEAST (http://www.ijeast.com)}

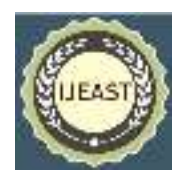

\section{CONCLUSION}

Multi-mode seismic response control of the regular chimney installed with tuned mass dampers (TMDs) is presented. Comparison of the responses is made for the chimney installed with single-TMD (STMD) controlling the first mode, and systematically MTMDs along with the height of the chimney under the El Centro, 1940 (N-S component)' earthquake excitations. The following conclusions are drawn from the results of the numerical study:

1. In general, the displacement and acceleration responses at the topmost node of the RC chimney are reduced when the STMD, MTMDs are installed.

2. Displacement of the fifth node is reduced as the percentage of damping increases but the displacement of other node increases with an increase in damping ratio

3. Node 5 is in vibration even after 200 seconds for the regular chimney vibration of the fifth node are eliminated by using STMD only. As the percentage of damping increases the time required to minimize the vibration at the fifth node reduces.

4. The effectiveness of installing the TMDs depends on the nature of the excitation. Maximum reduction of about $33 \%$ in the peak displacement at the topmost node of the RC chimney is achieved for the MTMD placed at $5^{\text {th }}$ and $4^{\text {th }}$ node under the El Centro, 1940 (N-S component) earthquake excitations.

5. As seen from their lesser normalized stroke, the positioning of the TMDs along the height of the chimney has a significant effect on its seismic response. Thus, tuning the TMD with the fundamental frequency, while placing it at the lower node may not be effective in seismic response control.

6. The reduction in the displacement is improved under earthquakes by increasing the mass ratio of the TMDs and the suitable mass ratio of $1.5 \%$ is recommended for improved vibration response control.

The damping energy in case of the MTMDs is always much greater than the uncontrolled case; thereby, the effectiveness of the multi-mode control strategy using the MTMDs in enhancing damping energy in the system is confirmed.

\section{Acknowledgement}

I take this opportunity to express my deep sense of gratitude towards my guide J. P. Patankar, Professor, Applied Mechanics Department, Government College of Engineering, Karad.

I extent my sincere thanks to Dr. A. T. Pise, Principal, Government College of Engineering, Karad and Dr. Y. M. Ghugal, Head, Applied Mechanics Department, Government College of Engineering, Karad for providing institutional facilities and extending all kinds of cooperation. I am thankful to all the faculty members of Applied Mechanics, Civil Engineering Department and Library whose guidance and help have been immensely useful in my work.

\section{REFERENCE}

[1] Brownjohn JMW, Carden EP, Goddard CR, Oudin G. (2010)"Real-time performance monitoring of tuned mass damper system for a 183 m reinforced concrete chimney," Wind Eng Ind Aerodyn;98(3): 169-79.

[2] Chang CC. (1999)"Mass dampers and their optimal designs for building vibration control," Eng. Struct.;21(5):454-63.

[3] Chen G, Wu J. (2001)“Optimal placement of multiple tuned mass dampers for seismic structures," J Struct. Eng. ASCE;127(9):1054-62.

[4] Den Hartog, J. P. (1947). "Mechanical vibrations," McGraw-Hill, New York, N.Y.

[5] Elias S, Matsagar V.( 2014) "Distributed multiple tuned mass dampers for wind vibration response control of high-rise building, " J wind Eng.

[6] Elias S, Matsagar V. (2014)“Wind response control of a 76-storey benchmark building installed with distributed multiple tuned mass dampers," J Wind Eng.;11 (2):37-49.

[7] Kwok KCS, "Samali B.( 1995) "Performance of tuned mass dampers under wind loads," Eng. Struct.;17(9):65567.

[8] Longarini N, Zucca M.( 2014) “A chimney's seismic assessment by a tuned mass damper," Eng. Struct.;79:290-6.

[9] Moon KS.( 2010) "Vertically distributed multiple tuned mass dampers in tall buildings: performance analysis and preliminary design," Struct. Des Tall Special Build;19(3):347-66.

[10] Pinkaew T, Lukkunaprasit P, Chatupote P(2003) "Seismic effectiveness of tuned mass dampers for damage reduction of structure," Engineering Structures 25,pp39. 46

[11] Sadek Fahim, Mohraz Bijan(1997) "A method of estimating the parameters of tuned mass dampers for seismic applications," Earthquake Engineering and Structural Dynamics Vol.26 pp 617-635

[12] Villaverde R, Koyama LA. (1993)“Damped resonant appendages to increase inherent damping in buildings," Earthquake Engineering and Structural Dynamics; 22:491-507.

[13] Villaverde R. (1985)“Reduction in seismic response with heavily-damped vibration absorbers," Earthquake Engineering and Structural Dynamics; 13:33-2. 
International Journal of Engineering Applied Sciences and Technology, 2019

Vol. 4, Issue 3, ISSN No. 2455-2143, Pages 266-276

Published Online July 2019 in IJEAST (http://www.ijeast.com)

[14] Villaverde R.( 1994) "Seismic control of structures with damped resonant appendage," Proceedings 9th World Conference of Structural Control, Los Angeles, CA, USA, vol. WP-4,; 113-119.

[15] Saidi I, Mohammed A.D(2007) "Optimum design for passive tuned mass dampers using viscoelastic materials," Australian Earthquake Engineering Society Conference.

[16] Xiang P, Nishitani A. (2014)“Seismic vibration control of building structures with multiple tuned mass damper floors integrated," Earthquake Eng. Struct. Dynam.;43(6):909-25. 